\title{
Recurrent Vitreomacular Traction in a Patient Treated with Ocriplasmin: A Case Report
}

\author{
Andreas Katsanos (D) - Konstantina Gorgoli · Ioannis Asproudis • \\ Maria Stefaniotou
}

Received: September 7, 2020 / Accepted: October 15, 2020 / Published online: October 27, 2020

(C) The Author(s) 2020

\section{ABSTRACT}

Introduction: To describe a case of recurrent vitreomacular traction and macular edema that appeared both before and after the intravitreal injection of ocriplasmin.

Case Report: An 82-year-old monocular man presented with metamorphopsia and reduced vision of 1-week duration. The patient's general medical history was unremarkable. His ophthalmic history was significant for severe ocular trauma in the right eye in childhood that caused phthisis. The left eye had undergone uncomplicated phacoemulsification 3 months earlier and the 1-month postoperative best corrected visual acuity (BCVA) was logarithmic mean angle of resolution (logMAR) 0.0. There was no history of other ocular conditions. At presentation, BCVA was logMAR 0.2 and optical coherence tomography (OCT) revealed the presence of cystoid macular edema caused by vitreomacular traction (VMT). The patient was scheduled for intravitreal ocriplasmin injection.

A. Katsanos $(\square) \cdot$ I. Asproudis · M. Stefaniotou Ophthalmology Department, Faculty of Medicine, University of Ioannina, Ioannina, Greece e-mail: katsanos@uoi.gr

K. Gorgoli

Iris and Retina Private Practice, Ioannina, Greece
Prior to treatment, the vision improved spontaneously to logMAR 0.1, and no VMT could be detected with spectral domain (SD)-OCT. The ocriplasmin injection was deferred but 3 weeks later the patient presented again with metamorphopsia, while VMT was again evident on SD-OCT. Ocriplasmin was injected and 1 month later the BCVA reached logMAR 0.1 without VMT. However, at 2 months post injection the VMT reappeared and a conservative approach with observation and topical nepafenac administration was decided. At the 3-month post-injection visit there was no VMT. More than 3 years after the ocriplasmin injection there is still no evidence of VMT, the patient is free of metamorphopsia, and his BCVA is logMAR 0.0.

Conclusion: Separation of consecutive layers of the vitreous cortex (vitreoschisis) may account for recurrent VMT.

Keywords: Jetrea; Ocriplasmin; Vitrectomy; Vitreomacular adhesion; Vitreomacular traction; Vitreoschisis 


\section{Key Summary Points}

As the optimal treatment strategy for symptomatic vitreomacular traction (VMT) remains unclear, individualizing the therapeutic course of action for each patient is necessary.

In recent years, ocriplasmin administered intravitreally has been available for the treatment of VMTs that conform to certain morphological features.

As highlighted by the current case, vitreoschisis might affect the natural history of VMT, and potentially influence the response to ocriplasmin.

\section{DIGITAL FEATURES}

This article is published with digital features, including a summary slide, to facilitate understanding of the article. To view digital features for this article go to https://doi.org/10.6084/ m9.figshare.13090109.

\section{INTRODUCTION}

In the last several years it has become increasingly recognized that the structure and dynamic changes of the vitreous are significantly more complex than previously assumed [1-7]. Agerelated changes in the structure of the vitreous may lead to the formation of vitreomacular traction (VMT) [5, 6, 8, 9], a potentially sightthreatening condition that often calls for surgical intervention [10]. The introduction of ocriplasmin (Jetrea; ThromboGenics NV, Leuven, Belgium), a recombinant protein of the protease plasmin that severs VMTs by acting on connective tissue elements of the vitreoretinal interface such as fibronectin and laminin [11], has offered a minimally invasive treatment option $[10,12]$.
The aim of this article is to present a case with unusual response to the intravitreal administration of ocriplasmin for the treatment of VMT.

\section{CASE REPORT}

An 82-year-old monocular man attended the outpatient unit with complains of metamorphopsia and reduced vision of 1-week duration in his only eye. The patient's general medical history was significant for arterial hypertension treated with metoprolol, balloon angioplasty, and cardiac pacemaker insertion several years previously. His ophthalmic history was significant for severe ocular trauma in the right eye in childhood, which eventually caused phthisis. His left eye had undergone uncomplicated phacoemulsification 3 months previously in our center and according to the patient's charts the 1-month postoperative best corrected visual acuity (BCVA) was logarithmic mean angle of resolution (logMAR) 0.0. There was no history of other ocular conditions. Written informed consent for the publication of this report was obtained from the patient.

At presentation, the patient's BCVA was logMAR 0.2, the Amsler test was positive, and cystoid macular edema was evident. The rest of the ophthalmic examination was unremarkable. Optical coherence tomography (OCT) revealed the presence of cystoid macular edema due to VMT (Fig. 1a). No breaks were found at the peripheral retina. On the basis of these findings, the patient was scheduled for ocriplasmin injection. On the day the ocriplasmin injection was scheduled, the patient reported that his vision had spontaneously improved. Indeed, BCVA was logMAR 0.1 and no VMT could be detected (Fig. 1b). Consequently, the ocriplasmin injection was not administered.

Three weeks later the patient presented with complains of metamorphopsia, while VMT was evident on OCT (Fig. 1c). Ocriplasmin was injected, and at the 1-month post-injection visit the patient's BCVA was logMAR 0.1 without evidence of VMT (Fig. 1d). However, at the 2-month post-injection visit, VMT reappeared 
(Fig. 1e). After counseling with the patient, conservative management with observation and topical administration of nepafenac three times daily was advocated.

At the 3-month post-injection visit there was no VMT, while BCVA was logMAR 0.0 (Fig. 1f). More than 3 years after the ocriplasmin injection the patient is free of metamorphopsia and VMT, while BCVA remains logMAR 0.0.
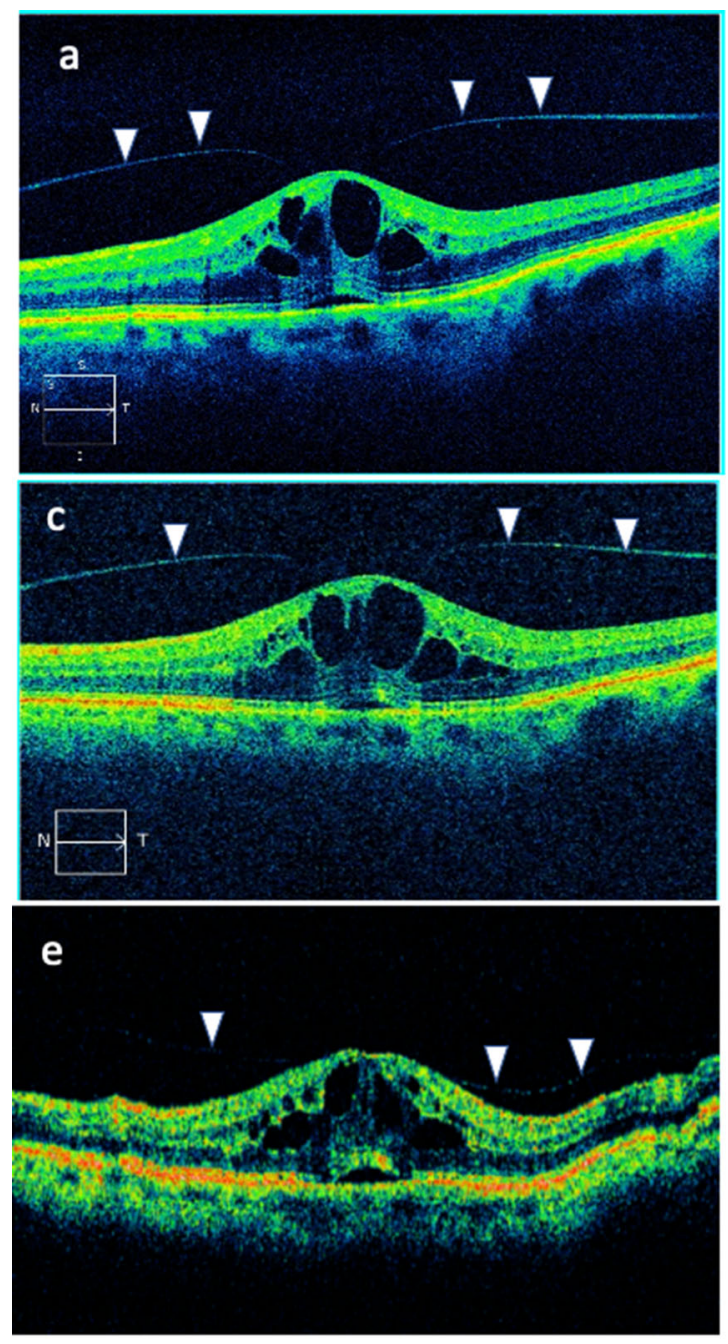

Fig. 1 a-f Optical coherence tomography (OCT) imaging for the reported case. Figures a and $\mathbf{c}$ were acquired using a Zeiss spectral domain OCT, whereas all other figures were

\section{DISCUSSION}

The vitreous gel is composed predominantly of water (approximately 98\%), collagen fibrils, and hyaluronic acid (HA) [1]. Several collagen types can be identified in the vitreous; however, the main ingredients of the collagen fibrils consist of types V/XI, II, and IX. A network of collagen fibrils forms a skeleton-like structure that maintains its volume with the interference of HA, which is highly hydrophilic [2]. Topographically, the vitreous is divided into two parts: the central vitreous and the cortex. The latter has the highest vitreal concentration of
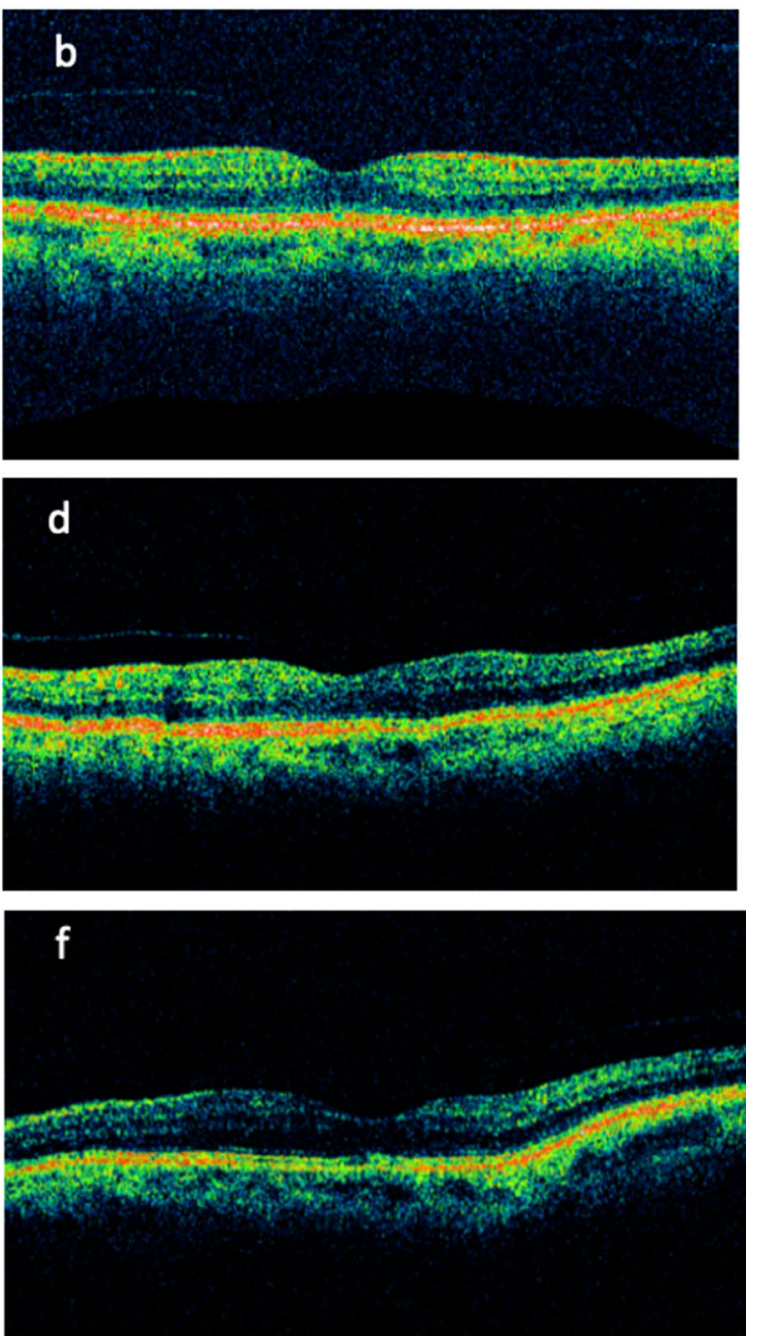

acquired using a Status OCT device. Vitreomacular traction is indicated with arrowheads 
collagen and HA [2]. Posteriorly, the vitreous cortex adheres to the inner limiting membrane (ILM) of the retina via extracellular matrix proteins such as laminin, fibronectin, and opticin [3]. The collagen of the posterior vitreous cortex is not organized in a monolayer as previously thought but seems to have a multilamellae structure [4]. Vitreoschisis refers to the separation of the posterior vitreous cortex lamellae, thus creating two distinct layers: the anterior towards the vitreous and the posterior towards the retina.

Age-related processes transform the vitreous from a solid gel in youth to a mostly liquified substance in adults over 40 years old [5]. Vitreous liquefaction (synchisis) is considered to be caused by gradual degeneration and collapse of collagen fibrils into parallel bundles within the central vitreous [6]. The liquified vitreous becomes unstable and collapses upon itself (syneresis) [7]. Posterior vitreous detachment (PVD) occurs when the vitreous is separated from the retinal surface primarily due to the age-related processes of liquefaction and dehiscence. The clinical manifestations of anomalous PVD depend upon the location of the strongest vitreoretinal adhesions. At the periphery, anomalous PVD induces retinal tears and detachments. At the macula, anomalous PVD may cause vitreoschisis with macular pucker, macular holes, VMT syndrome, or may contribute to diabetic macular edema [8]. Partial PVD with perifoveal vitreous cortex detachment and obstinate vitreal attachment to the fovea characterizes all types of VMT [9]. The therapeutic options for symptomatic VMT include observation, enzymatic vitreolysis with ocriplasmin, mechanical gas tamponade, and pars plana vitrectomy [10].

Ocriplasmin is a $27-\mathrm{kDa}$ recombinant protein of the human serine protease plasmin, which acts on fibronectin and laminin of the vitreoretinal interface [11]. The efficacy and safety of ocriplasmin for the treatment of VMT and full-thickness macular hole (FTMH) were established in two phase III clinical trials: the Microplasmin for Intravitreal Injection Traction Release without Surgical Treatment (MIVITRUST) study and the Ocriplasmin for Treatment of Symptomatic Vitreomacular Adhesion
Including Macular Hole (OASIS) study $[12,13]$. Ideally, patients considered for ocriplasmin treatment should be phakic, younger than 65 years, without epiretinal membrane (ERM) or diabetic retinopathy, having a VMT width that measures less than $1500 \mu \mathrm{m}$, or an FTMH smaller than $250 \mu \mathrm{m}$ [14]. Adverse events observed after the use of ocriplasmin include visual acuity reduction, zonular phacodonesis or dehiscence, retinal tear or detachment, and retinal toxicity [15].

In our case, the decision to treat the VMT with ocriplasmin was based on multiple factors: the patient had no other ocular disorders, the VMT was narrower than $1500 \mu \mathrm{m}$, the macula was edematous, the symptoms were quite bothersome, and the patient preferred a nonsurgical option for his only eye. Both the retinal traction and accompanying edema subsided spontaneously before treatment, but the improvement was temporary. As the VMT reappeared, enzymatic vitreolysis was performed. Unfortunately, despite the initial success, regression to the pre-treatment state occurred soon. Observation was advised at the time, while complete and permanent regression was observed at 3 months post injection.

We believe that the recurrent vitreomacular traction observed in our patient is the result of vitreoschisis: successive layers of the posterior vitreous cortex were detached while traction was exerted at the macula. The goal of pharmacological vitreolysis is to induce liquefaction of the vitreous gel while promoting its complete dehiscence from the retina $[12,14,16]$. To be successful, pharmacological vitreolysis should induce these two events simultaneously, or at least ensure that liquefaction does not progress without sufficient vitreoretinal dehiscence [10, 12-14, 16].

Incomplete posterior vitreoschisis has been described in patients with VMT $[17,18]$. According to the literature, VMT resolution after ocriplasmin administration has a suboptimal outcome in $30-40 \%$ of cases [12, 16]. Besides, in $30 \%$ of patients, the VMT settles spontaneously without any treatment $[19,20]$.

Our case highlights the uncertainties that clinicians may face when managing patients with VMT. In certain instances, it may be 
impossible to determine if an apparent VMT exists in a schisis-prone vitreous cortex. As indicated by our case, the effectiveness of ocriplasmin in alleviating VMT may be suboptimal over the long term in such eyes. In our case, the differential diagnosis should include pseudophakic cystoid macular edema (Irvine-Gass syndrome) [21]. However, our patient had macular edema only in the presence of vitreomacular traction, but never without it. This strongly suggests that our patient's clinical findings were due to vitreoschisis, rather than the Irvine-Gass syndrome.

In agreement with currently available data, our report suggests that ocriplasmin results may be unpredictable. However, it needs to be acknowledged that certain characteristics of our patient (age over 65 years, pseudophakia) might have limited the efficacy of this treatment.

\section{CONCLUSION}

The possibility of vitreoschisis should always be considered when using pharmacological vitreolysis for VMT. As vitreous dynamics are more complex than previously thought [2, 4, 8, 9], the use of ocriplasmin should be considered in carefully selected patients. In many cases, observation may be all that is needed.

\section{ACKNOWLEDGEMENTS}

The authors would like to thank the patient of this report.

Funding. No funding or sponsorship was received for this study or publication of this article.

Authorship. All named authors meet the International Committee of Medical Journal Editors (ICMJE) criteria for authorship for this article, take responsibility for the integrity of the work as a whole, and have given their approval for this version to be published.

Disclosures. Andreas Katsanos: honoraria/congress expenses from Cooper, Vianex,
Santen, Zwitter; research support from Laboratoires Théa. Konstantina Gorgoli, Ioannis Asproudis and Maria Stefaniotou report no disclosures.

Compliance with Ethics Guidelines. Written informed consent for the publication of this report was obtained from the patient.

Data Availability. Data sharing is not applicable to this article as no datasets were generated or analyzed for this article.

Open Access. This article is licensed under a Creative Commons Attribution-NonCommercial 4.0 International License, which permits any non-commercial use, sharing, adaptation, distribution and reproduction in any medium or format, as long as you give appropriate credit to the original author(s) and the source, provide a link to the Creative Commons licence, and indicate if changes were made. The images or other third party material in this article are included in the article's Creative Commons licence, unless indicated otherwise in a credit line to the material. If material is not included in the article's Creative Commons licence and your intended use is not permitted by statutory regulation or exceeds the permitted use, you will need to obtain permission directly from the copyright holder. To view a copy of this licence, visit http://creativecommons.org/licenses/by$\mathrm{nc} / 4.0 /$.

\section{REFERENCES}

1. Sebag J. Macromolecular structure of vitreous. Prog Polym Sci. 1998;23:415-46.

2. Sebag J. Anomalous posterior vitreous detachment: a unifying concept in vitreo-retinal disease. Graefes Arch Clin Exp Ophthalmol. 2004;242:690-8.

3. Sebag J, Hageman GS. Interfaces. Eur J Ophthalmol. 2000;10:1-3.

4. Gupta P, Yee KM, Garcia P, et al. Vitreoschisis in macular diseases. Br J Ophthalmol. 2011;95:376-80.

5. LeGoff MM, Bishop PN. Adult vitreous structure and postnatal changes. Eye. 2008;22:1214-22. 
6. Sebag J. Age-related changes in human vitreous structure. Graefes Arch Clin Exp Ophthalmol. 1987;225:89-93.

7. Lund-Andersen H, Sander B. The vitreous. In: Kaufman P, Alm A, editors. Adler's physiology of the eye. St. Louis, Missouri, USA: Mosby; 2002. p. 293-316.

8. Sebag J. Vitreoschisis. Graefes Arch Clin Exp Ophthalmol. 2008;246:329-32.

9. Duker JS, Kaiser PK, Binder S, et al. The International Vitreomacular Traction Study Group classification of vitreomacular adhesion, traction, and macular hole. Ophthalmology. 2013;120:2611-9.

10. Yu G, Duguay J, Marra KV, et al. Efficacy and safety of treatment options for vitreomacular traction: a case series and meta-analysis. Retina. 2016;36: 1260-70.

11. Bishop PN. Structural macromolecules and supramolecular organization of the vitreous gel. Prog Retin Eye Res. 2000;19:323-44.

12. Stalmans P, Benz MS, Gandorfer A, et al. Enzymatic vitreolysis with ocriplasmin for vitreomacular traction and macular holes. N Engl J Med. 2012;367(7): 606-15.

13. Dugel PU, Tolentino M, Feiner L, Kozma P, Leroy A. Results of the 2-year ocriplasmin for treatment for symptomatic vitreomacular adhesion including macular hole (OASIS) randomized trial. Ophthalmology. 2016;123(10):2232-47.

14. Haller JA, Stalmans P, Benz MS, et al. Efficacy of intravitreal ocriplasmin for treatment of vitreomacular adhesion: subgroup analyses from two randomized trials. Ophthalmology. 2015;122(1): 117-22.
15. Hahn P, Chung MM, Flynn HW, et al. Safety profile of ocriplasmin for symptomatic vitreomacular adhesion: a comprehensive analysis of premarketing and postmarketing experiences. Retina. 2015;35(6):1128-34.

16. Chatziralli I, Theodossiadis G, Xanthopoulou P, Miligkos M, Sivaprasad S, Theodossiadis P. Ocriplasmin use for vitreomacular traction and macular hole: a meta-analysis and comprehensive review on predictive factors for vitreous release and potential complications. Graefes Arch Clin Exp Ophthalmol. 2016;254:1247-56.

17. Carpineto P, Ciancaglini M, Aharrh-Gnama A, Cirone D, Mastropasqua L. Optical coherence tomography imaging of surgical resolution of bilateral vitreomacular traction syndrome related to incomplete posterior vitreoschisis: a case report. Eur J Ophthalmol. 2004;14(5):438-41.

18. Figus M, Carpineto P, Romagnoli M, Ferretti C, Di Antonio L, Nardi M. Optical coherence tomography findings of incomplete posterior vitreoschisis with vitreomacular traction syndrome and impending macular hole: a case report. Eur J Ophthalmol. 2008;18(1):147-9.

19. John VJ, Flynn HW Jr, Smiddy WE, et al. Clinical course of vitreomacular adhesion managed by initial observation. Retina. 2014;34:442-6.

20. Tzu JH, John VJ, Flynn HW Jr, et al. Clinical course of vitreomacular traction managed initially by observation. Ophthalmic Surg Lasers Imaging Retina. 2015;46:571-6.

21. Minnella AM, Savastano MC, Zinzanella G, et al. Spectral-domain optical coherence tomography in Irvine-Gass syndrome. Retina. 2012;32:581-7. 